\title{
Contrastive focus reduplication and the modification puzzle
}

\author{
Fabian Bross ${ }^{1}$ and Katherine Fraser ${ }^{2}$ \\ 1 University of Stuttgart, Stuttgart, DE \\ 2 University of the Basque Country (UPV/EHU), Vitoria-Gasteiz, ES \\ Corresponding author: Fabian Bross (fabian.bross@ling.uni-stuttgart.de)
}

\begin{abstract}
In this short paper we present a so far unnoticed syntactic constraint on contrastive focus reduplication (CR), a phenomenon that restricts the semantics of the reduplicated element to a prototypical meaning (but has other uses as well): The CR construction cannot be modified. In the case of nominal CR, this means that adjectival modification is blocked, as in *black CoffEEcoffee. We present data from English and German to support our claim and highlight how earlier accounts fail to capture the syntactic restriction. We then provide a sketch of an analysis couched with a Cartographic framework, tentatively proposing that CR results either (i) from cyclical movement of phrasal material through the specifiers of functional projections into the specifier of a focus phrase or (ii) by directly moving phrasal material into the specifier of a focus phrase.
\end{abstract}

Keywords: Contrastive focus; contrastive focus reduplication; reduplication; German; English; compounding; identical constituent compound; real-X reduplication; cartography

\section{Introduction}

This short article discusses contrastive focus reduplication (CR) in German and English. Also called the "double construction" (Dray 1987; Horn 1993) or "lexical cloning" (Horn 2006; Huang 2015), CR concerns the reduplication of a lexical item to single out a default or prototypical meaning in which one of the duplicates receives contrastive (focal) stress (Ghomeshi et al. 2004). CR has been analyzed as head movement into a CR projection (Ghomeshi et al. 2004 and similarly Travis 2003) and, especially in the German literature, as a word formation process, or to be more precise, as compounding (see, for example, Hohenhaus 2004; Stolz 2009; Finkbeiner 2012; 2014; Kentner 2017). In this squib we provide evidence that both accounts, especially the compounding analysis, cannot be correct and instead propose that CR involves phrasal focus movement. Although we will show that the head-movement and the compounding account cannot be on the right track, our own account also faces some unsolved issues that will be discussed.

This squib is structured as follows. In Section 2 we introduce the basic properties of CR with English and German examples and discuss the semantics of CR. Section 3 outlines previous accounts of CR for all parts-of-speech, particularly for English and German, plus the problems these accounts face. In Section 4, we argue that nominal CR blocks adjectival modification, a constraint which has been overlooked so far and which none of the previous accounts predict. In Section 5 we propose an analysis of nominal CR as DP-internal focus movement, which, inter alia, accounts for the modification-constraint data. We then apply this analysis to other parts-of-speech undergoing CR in Section 6. Section 7 concludes. 


\section{The phenomenon}

Contrastive focus reduplication (CR) is an understudied phenomenon involving the reduplication of a word or a larger constituent. The most thorough descriptions of CR have been for English (Ghomeshi et al. 2004) and German (though often under a different name, "identical constituent compounds" Hohenhaus 2004; Finkbeiner 2014; Kentner 2017 or "real-X total reduplication" Stolz 2009). Otherwise, CR has been noted for several different languages: Italian (Medici 1959; Wierzbicka 1991), Spanish (Horn 1993; Mau 2002; Roca \& Suñer 1998), French (Mau 2002), Persian (only with adjectives, Ghomeshi et al. 2004), Russian (Ghomeshi et al. 2004), or Kinande (only with nouns, Mutaka \& Hyman 1990). Additionally, reduplication with an intensifying function similar to CR seems to be a crosslinguistically widespread phenomenon, especially in creole languages (cf. Kouwenberg 2003; Haspelmath \& the APiCS consortium 2013). ${ }^{1}$

In Section 2.1, we will present a defining property of the phenomenon, observed crosslinguistically, then particulars for English and then for German. Section 2.2 will describe the semantics of the phenomenon.

\subsection{General properties of $C R$}

The most striking feature of CR is that one of the constituents receives intonational stress; the content of this item is then focalized (more in the following subsection). In the Ghomeshi et al. (2004: 308) paper, also called the SALAD-salad paper, they provide the example we have in (1).

(1) I'll make the tuna salad, and you make the SALAD-salad.

In (1), the first instance of salad is focus-marked (here, indicated with small capitals), and the second is unstressed. That one instance is stressed and the other one is unstressed is the common realization of CR cross-linguistically. As the function of CR is to restrict the meaning of a lexical item, it cannot target functional elements, only content words. This is illustrated in (2) (examples from Ghomeshi et al. 2004: 313).

a. *Are you sick, or ARE-are you sick?

b. *I didn't just read the book, I read THE-the book.

For English, Ghomeshi et al. (2004) note that CR targets besides nouns, also verbs (3a), adjectives (3b), verb particles (3c), proper names (3d), possessive pronouns ${ }^{2}(3 e)$, and lexicalized expressions (3f). Examples from Ghomeshi et al. (2004: 308).
a. Do you LIKE-like him?
b. Is he FRENCH-French?
c. I'm up, I'm just not UP-up.
d. That's not AUCKLAND-Auckland, is it?
e. This car isn't MINE-mine; it's my parents'.
f. Oh, we're not LIVING-TOGETHER-living-together.

\footnotetext{
${ }^{1}$ An example from Bahamian Creole is given in (1), taken from Hackert (2013).

(i) $\quad[\ldots]$ when it get dark-dark night [...].

'[...] when it gets really dark [...].'

Unfortunately, to-date no information about the stress patterns of such constructions is available. ${ }^{2}$ It seems that CR cannot attach to personal pronouns alone, although it seems to be marginally possible to
disambiguate between an inclusive and an exclusive reading (e.g., wE-we are going, but I don't know whether
you will join us, too).
} 
Also for English, Ghomeshi et al. (2004) discuss that CR can not only target whole words (4a), but also words without their inflectional morphology (4b). However, this is not the case with irregular forms, cf. (4) vs. (5).
a. GLOVES-gloves
b. GLOVE-gloves
a. GEESE-geese

b. *GOOSE-geese

Finally, Ghomeshi et al. (2004) note that CR can attach to bigger lexical units, namely verbs/adjectives plus object pronouns (6a), but only with unstressed pronouns, not proper names (6b).
a. Do you LIKE-HIM-like-him?
b. *Do you LIKE-PETER-like-Peter?

The empirical landscape is different in German, where CR can only target entire lexical items (i.e., words including their inflectional morphology). This means that nouns (7a), adjectives (7b), verbs (7c), and adverbs (7d) are eligible, but unlike (4b), both constituents must be inflected the same, cf. the examples in (8). ${ }^{3}$

a. Ich will KAFFEE-Kaffee und nicht diese Instantbrühe!

I want coffee-coffee and not this instant.broth

'I want a COFFEE-coffee and not this instant broth.'

b. Ich fahre ein gelbes Auto, also ein GELBES-gelbes Auto.

I drive a yellow car well a yellow-yellow car

'I drive a yellow car, well a YELLOW-yellow car.'

c. Willst du KOCHEN-kochen oder machen wir was aus der Dose? Want you cook-cook or make we something from the can

'Do you want to COOK-cook or should we make something from a can?'

d. Er hat nicht einfach laut geatmet, er hat LAUT-laut geatmet. He has not simply loudly breathed he has loudly-loudly breathed 'He did not just breathe loudly, he breathed LOUDLY-loudly.'

(8)
a. MANN-Mann
'MAN-man'
b. *MÄNNER-Mann
'MEN-man'
c. *MANN-Männer
'MAN-men'
d. MÄNNER-Männer
'MEN-men'

Unlike for English (3f), for German it is not clear whether it is possible to reduplicate larger constituents (9). Namely, we informally surveyed German speakers on this data

\footnotetext{
${ }^{3}$ Note that the example in (8b), Männer-Mann, works as a regular compound in German (for example meaning 'man who is interested in men'). In other words, it lacks this restricted or prototypical meaning seen in the other examples.
} 
point and judgments vary wildly for these types of sentences (note that there are two weak pronouns in the example).

(9) ?MAGST-DU-IHN-magst-du-ihn?

'Do you like him?'

In sum, the biggest difference between English and German is that English is more morphosyntactically permissive in terms of what CR can target. The next section will turn to the semantic properties of the phenomenon, consistent across languages.

\subsection{Semantic features of $C R$}

In the CR literature, the phenomenon has been described to semantically restrict the interpretation of the newly formed lexical item to a prototypical, quintessential or "real" reading. See the example from Ghomeshi et al. (2004: 308) in (1), repeated here as (10).

(10) I'll make the tuna salad, and you make the SALAD-salad.

'I'll make the tuna salad, and you make the (prototypical) green salad.'

The interpretation of (10) would then be that the addressee is told to make a prototypical salad. That is, a salad with many greens, in contrast to, e.g., a tuna salad which typically consists of tunafish and mayonnaise and maybe some vegetables like pickles, celery, or onion.

We follow Song \& Lee (2011), who argue that the contrastive focus provides exhaustive implication of a prototype, selecting a denotation out of a contextually-provided disjunct. For (10), this disjunct would be "tuna salad" or "green salad"; the former is excluded with contrastive focus on salad. Importantly, their analysis can also account for variations what the contrastive focus can target, as there exist more than just the SALAD-salad case for this phenomenon; cf. (11)-(13).

(11) Focus: Prototype of a category (SALAD-salad)

a. John: Can I get you a wine?

Mary: No, I was craving a DRINK-drink. Can you get me a martini?

b. John: Can I get you a soda?

Mary: No, I was craving a DRINK-drink. Can you get me a water?

(12) Focus: A (prototypical) subcategory within a category

a. Mary: Would you like a water?

John: No, a DRINK-drink. With alcohol.

b. Mary: Would you like a beer?

John: No, a DRINK-drink. I'll have some water.

(13) Focus: A (prototypical) category itself

a. Mary: It's really hot in here. I'd love a drink right now.

John: (handing him the lemonade prop) Here!

Mary: No, a DRINK-drink, silly!

b. Daughter: I want a bat for my birthday.

Dad: Aren't you afraid it will bite you?

Daughter: No, a BAT-bat. For playing baseball.

[Adapted from Song \& Lee 2011]

As seen in the examples above, the targeted element for the contrastively-focused drink changes depending on the situation. For the utterances in (11), it can be the prototype of 
alcoholic drinks (a), in which case it is the drink with a higher alcohol level, or it can be the prototype of non-alcoholic drinks (b), in which case the best exemplar is water. Because of this flexibility, CR can also be used to disambiguate between two readings of one surface form. For the utterances in (12), the use of CR references a subcategory of a category: in (a) the targeted subcategory is alcoholic drinks in contrast to non-alcoholic, while in (b) the targeted subcategory is non-alcoholic drink in contrast to alcoholic. Finally, in (13), the use of CR references a category itself: in (a) the target is a real (liquid/to-be-consumed) drink in contrast to a non-drinkable prop, while in (b) the target is a piece of sports equipment in contrast to an animal.

Song \& Lee (2011) account for the differences in reference levels with an intensional analysis. They argue against a scalar analysis, such as in Whitton (2006), the limits of which include seemingly ad-hoc dimensions. ${ }^{4}$ As the focus of this squib is not semantic, we leave aside a detailed discussion of a best analysis.

In general, it has to be noted that singling out a prototype is not the only function CR can fulfill. It has been noted in the literature, for example in Ghomeshi et al. (2004) or Horn (2018), that CR can also have an intensifying function. Additionally, CR is often used, as mentioned, to disambiguate the meaning of a lexical item. We will come back to such further functions and their importance for our own analysis later. The next section will present previous accounts of the phenomenon.

\section{Previous accounts}

There are two competing analyses for CR found in the literature: a head-movement account for English CR and a compounding account for German CR. In this short section, we present the basic notions of the analyses, then describe how they cannot capture the data.

In the English literature, Ghomeshi et al. (2004) analyze CR as a kind of head movement triggered by feature checking in a CR phrase (for a similar account see also Travis 2003). The main problems with a head-movement account is (i) it needs an additional functional category, i.e., a CR phrase, to explain the movement and (ii) it fails to account for data, such as that presented in Section 2.1, showing that CR in English targets not only heads, but larger constituents like a verb and a pronoun (6a), larger strings such as AFRAID-OFHIM-afraid-of-him (example from Ghomeshi et al. 2004: 326) or even idioms (Ghomeshi et al. 2004: 321 inter alia give the following example: OVER-THE-HILL-over-the-hill). As Ghomeshi et al. (2004: 351) themselves note, this analysis cannot be on the right track. ${ }^{5}$

In the German literature, CR has mainly been analyzed as compounding (e.g., Hohenhaus 2004; Finkbeiner 2014), i.e., as a morphological process. Arguments in favor of this analysis are the undeniable modifier-head structure that CR exhibits, a structure also found in compounds, and CR's stress pattern, which is similar to compounds. Additionally, the eligible categories for CR in German are exactly those categories which can combine to form compounds with another element of the same class: nouns, adjectives, verbs, and adverbs.

Arguments against a compound analysis were raised by Ghomeshi et al. (2004) for English and Freywald (2015) for German. Ghomeshi et al. (2004) argue that there are parts-of-speech in English which are not used in compounding, but can be targeted by CR. Freywald (2015) shows that compounding in German often involves linking elements which are banned in CR. Additionally, she notes that while it is possible to elide the second constituent of a compound in a N-N coordination structure, this is is not possible with CR. This is illustrated in (14) and (15).

\footnotetext{
${ }^{4}$ Another account would be to capture the prototype effect of CR within Relevance Theory (see, e.g., Barsalou 1983; 2010; Wilson 2004).

${ }^{5}$ Ghomeshi et al. (2004) also present an analysis in the parallel architecture framework based on Jackendoff (1997; 2002) which we will not discuss here.
} 


\author{
Instant- und Filterkaffee \\ 'instant and filter coffee' \\ *KAFFEE- und Filterkaffee \\ Intended: 'prototypical coffee and filter coffee'
}

Regarding the eligible categories: while it is true that $\mathrm{N}+\mathrm{N}, \mathrm{Adj}+\mathrm{Adj}, \mathrm{V}+\mathrm{V}$, and Adv $+\mathrm{Adv}$ compounds are found in German, only $\mathrm{N}+\mathrm{N}$ and $\mathrm{Adj}+\mathrm{Adj}$ compounds are productively used to form new words, while $\mathrm{V}+\mathrm{V}$ and $\mathrm{Adv}+\mathrm{Adv}$ compounds are rarely found in the language (cf. Freywald 2015 for a more detailed discussion). However, despite all these problems with a compound analysis, some authors still defend this view, mainly by arguing that German exhibits phrasal compounding which also lacks linking elements (e.g., Kentner 2017). As we will defend in the following sections, there is another way to analyse CR.

\title{
4 The modification puzzle
}

This section presents a puzzle which challenges previous accounts. Interestingly, there is one syntactic restriction with strong theoretical consequences in both German and English that has been overlooked so far: it is not possible to modify a CR construction. For the nominal domain, this means that adjectival modification is completely banned in CR. This might be partly explained by the fact that the first element in a nominal CR-construction has an adjectival flavor by itself. ${ }^{6}$ Crucially, a compounding analysis cannot account for modification being barred, as compounds generally allow modification. In the following, both the italicized German and translated English versions are ungrammatical with modification (16). Note that this incompatibility with modification appears to span across different types of modifiers: (non-)subsective/intersective adjectives all are incompatible when used as modifiers of CR. ${ }^{7}$

$$
\begin{aligned}
& \text { Ich will einen ("schwarzen/kostenlosen/heißen) } \\
& \text { I wAFFEE-Kaffee. } \\
& \text { 'I want a black/free/hot } \\
& \text { 'I want a (*black/free/hot) coFFEE-coffee.' }
\end{aligned}
$$

While adjectival modification is banned in nominal CR constructions, real intensification is allowed in German as well as in English, as illustrated in (17). Crucially, the fact that real intensification is possible also means that the modification-blocking effect does not simply arise for phonological reasons.

$$
\begin{aligned}
& \text { Paul ist so ein richtiger MANN-Mann. } \\
& \text { Paul is such a real man-man } \\
& \text { 'Paul is a real MAN-man.' }
\end{aligned}
$$

At first sight, this may be counter to previous claims that the meaning created by CR can be paraphrased with 'real/really X' (cf., for example, Freywald 2015: 916). However, real is a kind of veracity modifier, and considering that the semantic function of both CR and veracity modifiers is to refer to the best exemplar (Masià 2015), it is not surprising that this modifier is grammatical. In other words, real with CR expresses that the exemplar is truly an outstanding exemplar in some domain or category.

Even though nouns are typically able to be modified by (intersective) adjectives, this is not the case for CR, as seen in the example above. It is worth pointing out that although adjectival modification is banned, the element formed by nominal CR is still a DP as evidenced by the fact that coordination with another DP is possible. This is illustrated for

\footnotetext{
${ }^{6}$ Thanks to an anonymous reviewer for this observation.

${ }^{7}$ We also manually searched the CR corpus available at http://home.cc.umanitoba.ca/ krussll/redup-corpus.html (last accessed 11 November 2019) and found no modified instance of CR.
} 
German in (18a) (modified from Kentner 2017: 240) and for English in (18b) (modified from Ghomeshi et al. 2004: 308). Thus, while modification inside the DP is blocked, the whole structure is still a DP.
a. Nimmst du da $\left[_{\mathrm{DP}}\right.$ Basmatireis $]$ oder $\left[_{\mathrm{DP}}\right.$ REIS-Reis $]$ ?
Take you there basmati.rice or RICE-rice
'Do you like basmati rice or RICE-rice in this case?'

b. I'll make the tuna salad and you make $\left[_{D P}\right.$ the SALAD-salad $]$ and $\left[_{D P}\right.$ the dessert $]$.

Note that modification is not only banned in the nominal domain, but the same applies to other parts of speech undergoing CR. However, for the moment we will restrict the discussion to the nominal domain.

Before presenting our analysis, it is worth pointing out that adjectival modification with contrastive focus in general is not banned. This is illustrated by the minimal pair in (19).

\section{a. Contrastive focus}

A: Here is the yellow bike that was on your wish list.

B: Yellow bike? I wanted a yellow CAR!

b. Contrastive focus reduplication

A: Here is the yellow toy car you wanted.

B: Yellow toy car? *I wanted a yellow CAR-car!

The example shows that the modification-blocking effect arises from CR and is not a general property of contrastive focus. ${ }^{8}$

\section{An alternative analysis for nominal CR}

A plausible assumption for why adjectival modification is blocked in nominal CR is that the position in which the AdjP would be located otherwise is already occupied. If this assumption is on the right track, the question is: Which element is in this position? A good candidate is the first element of the CR construction itself that "has the aura of a modifier" (Ghomeshi et al. 2004: 343), similar to an adjective (see also Stolz, Stroh \& Urdze 2011: 202-204 for a similar claim for German CR). However, from a Cartographic perspective, there is not only one projection which is able to host an AdjP, but several (cf. Cinque 2010 and also Cinque 1999; 2006). As, semantically, each projection has its own semantic function and as CR restricts the meaning of the respective noun to a prototypical one, a tentative assumption is that all these positions are covertly filled.

Let's look at how this can be implemented. In Cartographic approaches, the internal structure of the DP consists of a rigidly ordered set of functional projections. This idea was derived from the fact that adjectives are not freely ordered, but are cross-linguistically fixed (cf. Whorf 1945; Kingsbury \& Wellman 1986; Sproat \& Shih 1991; Cinque 1994; Hole 2015: 1304-1308; van Gelderen 2017: 107-110). Each projection is able to host AdjPs from a specific set of semantic categories. For example, subjective evaluations of the noun referent are thought to be located very high up in the DP structure, while color adjectives are thought to be hosted very low down in the structure. In English, this leads to the fact that the order $\left[_{\mathrm{DP}} a\left[_{\mathrm{EvalP}}\right.\right.$ cute $\left[_{\mathrm{ColorP}}\right.$ black $\left[_{\mathrm{NP}}\right.$ cat $\left.\left.]\right]\right]$ is unmarked, while the order \# a black

\footnotetext{
${ }^{8}$ An anonymous reviewer remarked that there also seem to be modification restrictions with contrastive focus proper and gave the following example: *I want a free BLACK coffee, not a latté. To make the contrast more visible it is advisable to slightly modify the example and add another instance of free: *I want a free BLACK coffee, not a free latté. Focusing black inside the DP $\left[_{\mathrm{DP}}\right.$ free black coffee], however, requires overt movement as will be discussed in Section 5: I want a BLACK free coffee, not a free latté. Thus, there are no modification restrictions with contrastive focus in general, but there are ordering restriction to be obeyed.
} 
cute cat is marked and can only be used felicitously with comma intonation or for focusing purposes. When contrastively focused, many accounts assume that black moves into a DP-internal focus projection (e.g., Bhattacharya 1998; Scott 2002; Aboh 2004; Haegeman 2004; Laenzlinger 2005; Truswell 2005; Szendri 2012): $\mathrm{C}_{\mathrm{DP}} a \mathrm{C}_{\mathrm{FocP}}$ black $\mathrm{C}_{\mathrm{EvalP}}$ cute $\left[_{\text {ColorP }} t_{\mathrm{i}} \mathrm{L}_{\mathrm{NP}}\right.$ cat]]]]]. A partial representation of the internal structure of the DP is given in (20).

$$
\text { DP }>\text { FocP }>\text { EvalP }>\text { SizeP }>\text { ShapeP }>\text { ColorP }>\text { MaterialP }>\text { NP }
$$

We assume that the NP in a nominal CR construction moves in a cyclical fashion to the specifiers of all these projections, finally landing in SpecFocP (while leaving a copy of itself behind). This can explain the fact that nominal CR allows only a determiner-but no evaluative, size, shape, color, or other modification. In each projection, the moved copy acts as a modifier, modifying the meaning of the respective projection. This leads to a prototypical meaning.

The tree in (21) shows a simplified derivation of the KAFFEE-Kaffee example. The first element of this construction modifies its copy in a way that it has the material that is typical for a coffee, the typical color of a coffee, the typical size of a coffee, and so on (of course, contextual enrichment can also play a role in the final interpretation). This is achieved by moving the copy into the specifier of each functional projection in the DP structure until it lands in SpecFocP. Note that it is the whole NP that is being moved and not only the $\mathrm{N}^{\circ}$ (for this reason, the NP is highlighted in the structure). One could, of course, also assume that it is only the $\mathrm{N}^{\circ}$ that is moved, i.e., that CR is an instance of head movement. However, CR is also possible with elements that are phrases and not heads. Thus, we will, in the following, assume that it is always phrasal material which moves.

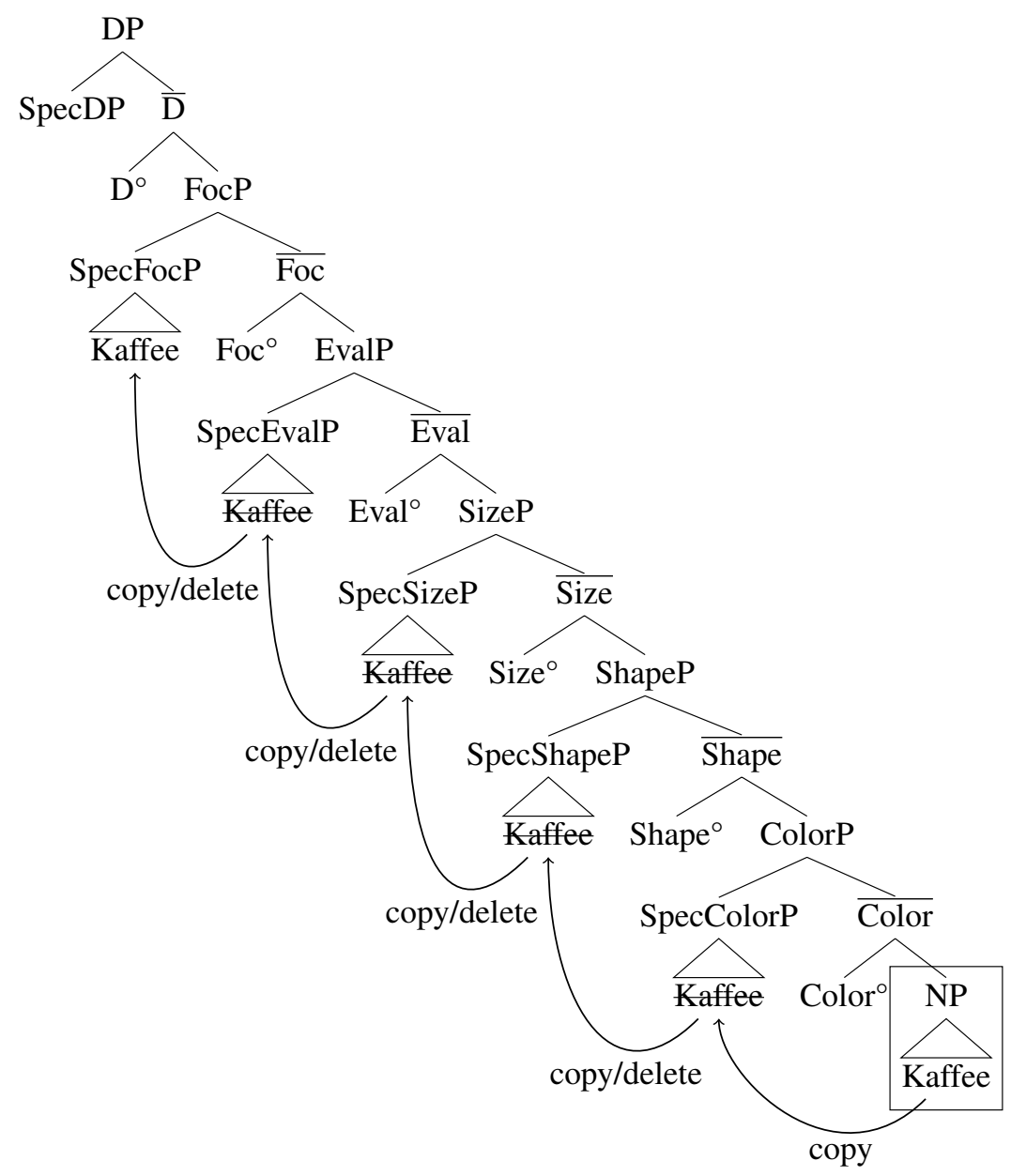


We can assume that the trigger for this movement is feature checking (or: valuation). To be more precise, the NP is moved to check a focus feature. At the same time feature checking in the form of spec-head agreement takes place on every landing site.

This does not only make sense semantically as it explains why CR "has the aura of a modifier" (Ghomeshi et al. 2004: 343), but also correctly predicts that adjectival modification is blocked as all possible positions for AdjP are occupied by silent copies. Additionally, we arrive at the correct stress pattern and correctly predict the absence of linking elements as we are not dealing with compounding.

Furthermore, a DP-internal focus-movement analysis also accounts for the fact that the intensifier richtig 'really' is not banned in nominal CR. Intensification has no fixed position inside the articulated DP, but can attach to any adjective in between the DP and NP, as long as it is the highest possible adjective. Intensifying a black cat yields a [really black] cat and intensifying a cute black cat yields a [really cute] black cat (but not \# a cute [really black] cat). Crucially, contrastively stressed elements occupying SpecFocP inside the DP structure can also be intensified, as in $\left[_{\mathrm{DP}} a\left[_{\mathrm{FocP}} \text { [really black }\right]_{\mathrm{i}}\left[_{\mathrm{EvalP}}\right.\right.$ cute $\left[_{\mathrm{ColorP}} t_{\mathrm{i}}\left[_{\mathrm{NP}}\right.\right.$ cat $\left.\left.\left.]\right]\right]\right]$. An alternative account would be to assume that the NP does not move cyclically to SpecFocP, but simply that the NP moves directly to SpecFocP. In this case, modification would be blocked because the two parts of the CR-construction form a unit. ${ }^{9}$ Again, both instances are spelled out. This modeling possibility is shown in the tree in (22). While this model, at first sight, has the disadvantage that is does not account for the semantics in the same way as the model in (21), we will see that it is easier to expand it to other parts of speech that can undergo CR.

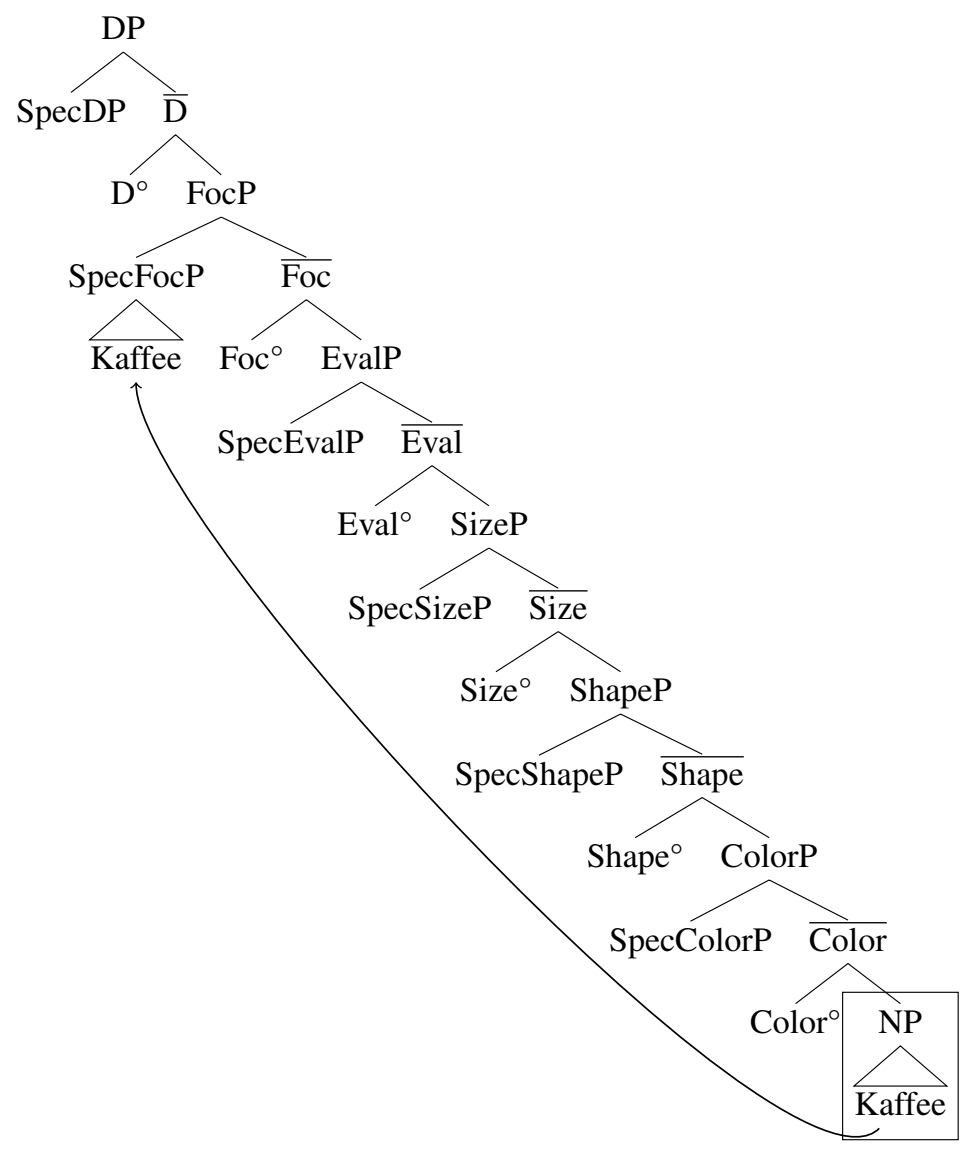

\footnotetext{
${ }^{9}$ This unit formation comes into being for semantic reasons. The structure KAFFEE-Kaffee refers to a single concept. Modifying this concept would require an adjective to be located in front of the whole construction. The only slot available, however, is one in between the two NPs. This would force the speaker to produce a structure in which only the non-focused part of the DP is modified. This would lead to an odd structure like "KAFFEE schwarzer Kaffee 'COFFEE black coffee'.
} 


\section{Extending the analysis to adjectives, verbs, and adverbs}

So far, the proposed analysis only accounts for CR in the nominal domain. The goal of the present section is to expand the analysis to adjectives, verbs, and adverbs.

Concerning adjectives, the analysis above works quite similarly. Instead of an NP moving to FocP, it is an AdjP that is copied and moved. This, again predicts that modification is blocked. And indeed this is on the right track as shown in (23).

(23) *Ich fahre ein schönes gelbes Auto, also ein schönes GELBES-gelbes Auto. I drive a nice yellow car well a nice YELLOW-yellow car 'I drive a nice yellow car, well a nice YELLOW-yellow car.'

Implementing the cyclical model turns out to be not easy as one would need to assume that gelbes 'yellow' from the example above would need to move from SpecColorP through, for example, SpecShapeP. The semantics that would be produced would be (informally) something like 'yellow in the shape of yellow'. This does not sound plausible. ${ }^{10}$ Moving the AdvP 'yellow' directly in SpecFocP, as proposed in the second account, however, works in a very similar way as proposed for nouns. This option is shown in the tree in (24).

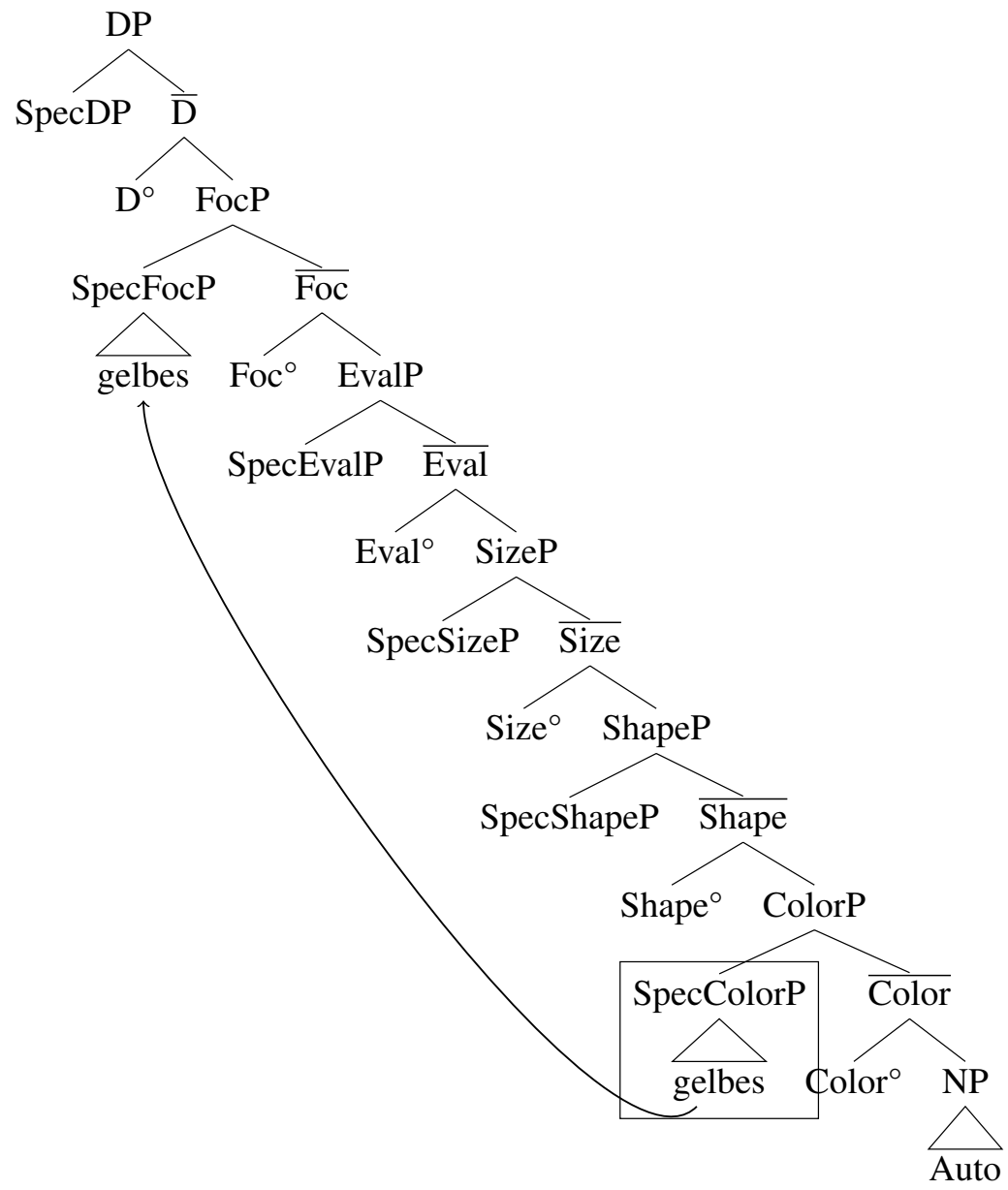

Again, we arrive at the correct stress pattern and can account for the fact that modification is banned. There is one important note to make concerning this example and the

\footnotetext{
${ }^{10}$ One could, however, alternatively assume that not all functional projections are present in each case. This would circumvent the problem of the production of implausible semantics (see Sigurðsson \& Maling 2012) for a discussion of the idea that not all functional projections are present in all cases.
} 
two modeling possibilities. It seems, as mentioned, not plausible to assume that the AdjP moves cyclically in this case. However, if we compare the yellow example with the coffee example, there is also a semantic difference. While COFFEE-coffee leads to a prototypical reading, YELLOW-yellow leads to an intensifying reading ('a really noticeable/salient yellow'). It thus seems, as if they were produced by two different structural processes (cyclic movement to SpecFocP vs. direct movement to SpecFocP). For now, however, we will stick to the direct movement option for the remaining parts-of-speech.

To extend the analysis to verbs, one needs to assume that with a verb undergoing CR the VP is moved into the specifier of a focus position located above the VP. Such a TP-internal focus projection was repeatedly proposed for independent reasons in the literature (e.g., Belletti \& Shlonsky 1995; Jayaseelan 2001; Belletti 2001; 2003). ${ }^{11}$ This account predicts that CR in the verbal domain is only possible with verbs located below the TP node. This prediction is indeed borne out, as examples including verbs undergoing CR always contain another, higher verb being located in the head of the TP (or some other higher projection) (25a), while inflected verbs hardly can undergo CR (25b).

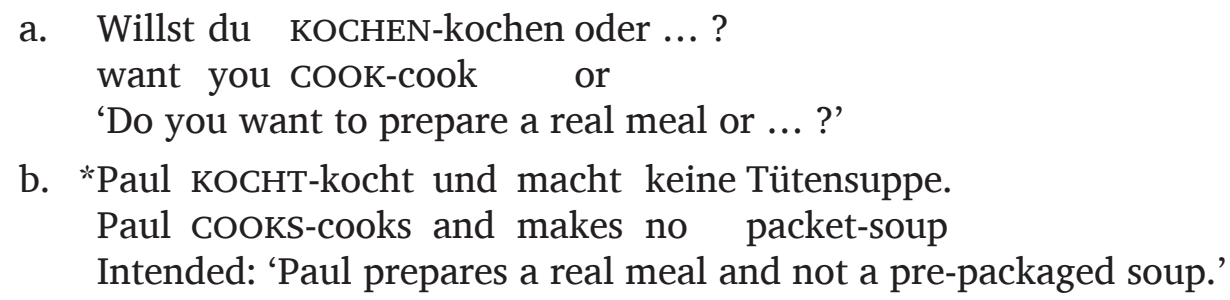

As illustrated in (25), it is only non-inflected verbs which undergo CR-a fact which can be accounted for by assuming that the CR-verb moves into a TP-internal focus position (cf. also the example in (2a), which also points into this direction in English). Similarly, it seems not to be possible for modal verbs to undergo CR. Although some modal verbs, e.g., deontic modals, are believed to be located below the TP they nevertheless need to move to $\mathrm{T}^{\circ}$ at some point in the derivation to check their tense features. The example in (26) shows that it is not possible to disambiguate an epistemic and a deontic modality reading with $\mathrm{CR}$.

\section{*MUSS-muss er arbeiten?}

MUST-must he work

Intended: 'Is he obliged to work or do you assume that he works?'

Finally, modification of the verb is blocked in a similar way to what we described in the nominal domain, as illustrated in (27).

\footnotetext{
*Sollen wir heute gemütlich KOCHEN-kochen?

Should we today comfortable COOK-cook

Intended: 'Should we prepare a real meal comfortably [e.g., relaxed at home] today?'
}

The proposed approach additionally predicts that it is only lower adverbs that are blocked as modifiers in verbal $\mathrm{CR}$, while adverbs taking scope above the TP should be fine. This is because they are positioned above the TP-internal focus projection. The example in (28) illustrates that this prediction is indeed borne out.

\footnotetext{
${ }^{11}$ We remain agnostic about the exact position of this focus projection and simply assume that it is located somewhere inside the TP/IP-domain.
} 
(28) Wenn Paul "schlafen" sagt, meint er meistens kuscheln. Aber heute will er when paul sleep says means he usually cuddle but today wants he angeblich SCHLAFEN-schlafen.

allegedly SLEEP-sleep

'When Paul says ‘to sleep' he usually means to cuddle. But today he allegedly wants to SLEEP-sleep.'

While the verb in (27) cannot be modified by the structurally low adverb gemütlich 'comfortable', the adverb angeblich 'allegedly' takes scope above the TP and therefore above the TP-internal focus projection.

A similar mechanism can be assumed for predicative adjectives in which the copular verb receives its inflection in the TP, while the main predicate is formed by an adjective. In this case, the AdjP hosting the adjective moves into the specifier of the TP-internal focus projection. An example of a predicative adjective undergoing CR is given in (29).

Paul is not simply drunk. He is DRUNK-drunk.

In this case we can assume the AdjP which hosts drunk in its specifier is being copied and moved into the specifier of the TP-internal FocP (we are not concerned here with the exact structural make-up of clauses containing predicative adjectives, but see Alexiadou 2014 for more details). Again, the positions between the two copies are blocked because they form a unit.

For adverbs a similar mechanism as for verbs can be assumed, i.e., we assume that AdvPs move into the specifier of a TP-internal FocP. Note that this would predict that adverbs above the TP (Cinque 1999), namely speaker-oriented adverbs, should not undergo $\mathrm{CR}$ and it is indeed hard to come up with naturally sounding examples, as illustrated in (30).

a. *HONESTLY-honestly, I don't want to go to the party.

b. *SURPRISINGLY-surprisingly, Paul has bought a new computer.

Again, we will assume that this movement is phrasal (not only because CR can attach to larger constituents, but also because we will follow a Cartographic approach inspired by Cinque 1999 in which adverbs are located in the specifiers of dedicated functional projections). Furthermore, we assume that speech-act-indicating adverbs are located in a projection which is above the projection for miratives (cf., for example, Tescari Neto 2013: 317; Varley 2014: 57-59; Alcázar 2016; Bross 2020), which again is located above the projection hosting evidential adverbs. These classes are thought of as being located above the TP (cf., Cinque 1999). Non-speaker-oriented adverbs are located in lower projections, i.e., in projections below the TP and tentatively below the TP-internal FocP. For reasons of simplicity, we will only use one projection for these adverbs and label it AdvP.

All relevant positions are shown for illustrative purposes in the tree in (31). Speakeroriented adverbs, like honestly, surprisingly, or allegedly cannot undergo CR as they are located above the TP-internal FocP, as shown in the tree. Similarly, verbs located in $\mathrm{T}^{\circ}$ cannot undergo CR for the same reason. Lower adverbs located in SpecAdvP, in contrast, can undergo CR as they are able to move up to SpecFocP (e.g., laut 'loudly' from the example in (7d)) as can verbs when the whole VP is moved into the specifier of FocP. We marked the specifier of the FocP, i.e., the assumed landing site of the verbs and adverbs undergoing $\mathrm{CR}$, with a big $\times$. 


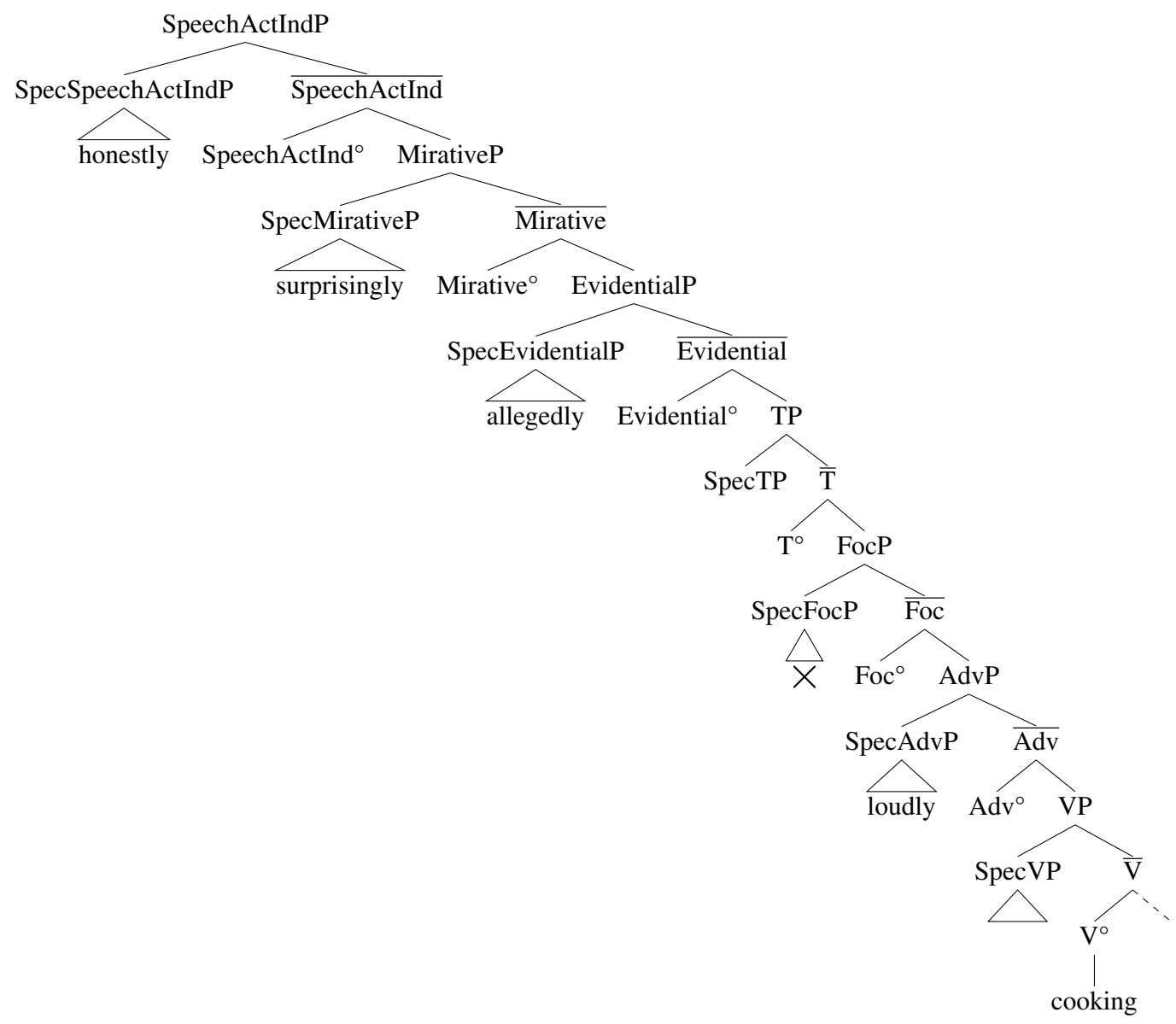

\section{Conclusion and Discussion}

In this squib we have argued, based on data from German and English, that CR cannot be a compounding process. The main reason to dismiss the compounding analysis was that it is impossible to modify a CR construction. This observation, however, directly follows if it is assumed that the position in which the modifier would be located is blocked. This was modeled in the Cartographic framework by assuming that the element undergoing CR is either (i) cyclically moved through all the possible modifying positions that are located in-between the copied element and the focus phrase into which the copy moves to or (ii) directly moved to the specifier of the focus phrase. At the same time both copies, the one that moves into SpecFocP and the one that stays put are spelled out. This does not only account for the fact that modification is blocked with $\mathrm{CR}$ or the stress pattern of the construction, but also for other restrictions concerning CR that were already described in the literature. For example, it accounts for the fact that linking elements are missing in nominal CR or for the fact that functional elements, like auxiliaries, cannot undergo CR, as they are located above the relevant FocP. Finally, this analysis captures the semantics of CR and explains why the literature on CR has repeatedly stressed that the first element in a CR construction has the feeling of a modifier and "contributes some kind of functional meaning" (Finkbeiner 2014: 188).

In Section 2.2 we have mentioned that one of the most salient functions of CR that has been discussed in the literature is to single out a prototype called the echt-icity function by Horn (2018). Crucially, he notes that this prototype function is closely related to nouns: "nominal clones tend to instantiate what Rosch (1978 et seq.) terms prototype" (Horn 2018: 242). However, we have also discussed that CR is often used to intensify a meaning. Interestingly, Horn (2018) shows that the intensification reading is mainly found with 
adjectives. This seems to fit in well with the idea that adjectives move directly to a focus position while nouns have the option to cyclically move through functional projections above them until they reach their focus position. The idea, that both movement options (direct focus movement versus cyclical focus movement) are available, however, remains an hypothesis so far, but future research should investigate whether there indeed is a correlation between the different functions of CR and different parts-of-speech (or, to be more precise, different functions correlating with different structural positions).

Still, there are some open questions. It is, for example, unclear why CR can attach to a verb plus a pronominal element (Do you LIKE-HIM-like him), but not to a verb plus another DP (*Do you LIKE-PETER-like-Peter) in English. While our current account does not explain this, we take this as evidence that CR involves phrasal movement instead of head movement. Although we leave open the question of how to exactly model this phenomenon it is worth pointing out that the answer to this unresolved issued may lie in the well-known fact that object pronouns occupy a syntactic position different from regular DPs (Larson 1988; Cardinaletti \& Starke 1999; Wallenberg 2008).

A further problem that was not mentioned so far is that CR in the nominal domain cannot attach to DPs with post-nominal PP complements/modifiers. ${ }^{12}$ Thus, it is not possible to have structures like *?STUDENT-OF-PHYSICS-student-of-Physics or *?STUDENT-WITHLONG-HAIR-student-with-long-hair. If it is indeed the whole NP that moves it is unclear why these structures are not well-formed. ${ }^{13}$

Another unresolved issue concerns the fact that it is unclear why English allows the reduplication of elements without inflectional material and German does not. Perhaps an account in the framework of Distributed Morphology (Halle \& Marantz 1993) could help shed light on this question (as already proposed by Ghomeshi et al. 2004).

A final critical point relates to the empirical basis of this paper. Although the intuitions about the inability of CR-constructions to be modified are very robust and are in line with the fact that existing examples are never modified (cf. Footnote 7), there is still a need more fine-grained research into what structures CR is able to create (also cross-linguistically). It is, for example, unclear whether it is possible to reduplicate larger chunks, like whole CPs, in German (cf. the unclear status of the example in (9)). We are confident that future research in this area may uncover more details about the exact structure of CR by using formal elicitation techniques.

\section{Acknowledgements}

We thank the editor, three anonymous reviewers and the following people: Artemis Alexiadou, Ellen Brandner, Elena Castroviejo, Chiara De Mitri, and Daniel Hole for valuable discussions (in alphabetical order). This research has been partially supported by Projects VASTRUD (PGC2018-096870-B-I00) and and predoctoral Grant BES- 2016-076783, funded by the Ministry of Science, Innovation and Universities (MiCIU)/Spanish Research Agency (AEI) and the European Regional Development Fund (FEDER, UE), by the IT1396-19 Research Group (Basque Government), and GIU18/221 (University of the Basque Country, UPV/EHU).

\footnotetext{
12 Thanks to an anonymous reviewer for pointing this out. thought. Cf. the displacement cases from De Kuthy \& Meurers (2001: 146) in (1).

(ii) a. A book was written about Nixon by John.

b. Ein Buch hat sich Hans über Syntax ausgeliehen. a book has REFLEXIVE Hans about syntax borrowed 'Hans borrowed a book on syntax.'
}

${ }^{13}$ While we cannot account for this observation it may be worth mentioning that it is well-known that the connection between nouns and their corresponding PP modifiers (e.g., Radford 1988; Keizer 2004) or their PP complements (e.g., Müller 1998; De Kuthy 1998; De Kuthy \& Meurers 2001) is often not as close as often 


\section{Competing Interests}

The authors have no competing interests to declare.

\section{References}

Aboh, Enoch O. 2004. Topic and focus within D. Linguistics in the Netherlands 21(1). 1-12. DOI: https://doi.org/10.1075/avt.21.04abo

Alcázar, Asier. 2016. Minor speech acts in a Basque mirative construction. Florida Linguistics Papers 3(1).

Alexiadou, Artemis. 2014. The syntax of adjectives. In Andrew Carnie, Dan Siddiqi \& Yosuke Sato (eds.), The Routledge handbook of syntax, 107-125. London: Routledge.

Barsalou, Lawrence W. 1983. Ad hoc categories. Memory \& cognition 11(3). 211-227. DOI: https://doi.org/10.3758/BF03196968

Barsalou, Lawrence W. 2010. Ad hoc categories. In Patrick Colm Hogan (ed.), The Cambridge encyclopedia of the language sciences, 87-88. New York: Cambridge University Press.

Belletti, Adriana. 2001. "Inversion" as focalization. In Aafke C. J. Hulk \& Jean Yves Pollock (eds.), Subject inversion in Romance and the theory of Universal Grammar, 60-90. Oxford: Oxford University Press.

Belletti, Adriana. 2003. Aspects of the low IP area. In Luigi Rizzi (ed.), The structure of CP and IP: The cartography of syntactic structures, 16-51. Oxford: Oxford University Press.

Belletti, Adriana \& Ur Shlonsky. 1995. The order of verbal complements. A comparative study. Natural Language and Linguistic Theory 13. 489-526. DOI: https://doi.org/10. 1007/BF00992739

Bhattacharya, Tanmoy. 1998. DP-internal NP movement. University College London Working Papers in Linguistics 10. 143-156.

Bross, Fabian. 2020. The clausal structure of German Sign Language: a Cartographic approach. Berlin: Language Science Press.

Cardinaletti, Anna \& Michal Starke. 1999. The typology of structural deficiency: a case study of the three classes of pronouns. In Henk Van Riemsdijk (ed.), Clitics in the languages of Europe, 145-233. Berlin: Mouton de Gruyter. DOI: https://doi.org/10. $1515 / 9783110804010.145$

Cinque, Guglielmo. 1994. On the evidence for partial N-movement in the Romance DP. In Guglielmo Cinque, Jan Koster, Jean-Yves Pollock, Luigi Rizzi \& Raffaella Zanuttini (eds.), Paths towards Universal Grammar: Essays in honor of Richard Kayne, 85-110. Washington: Georgetown University Press.

Cinque, Guglielmo. 1999. Adverbs and functional heads: a cross-linguistic perspective. New York \& Oxford: Oxford University Press.

Cinque, Guglielmo. 2006. Restructuring and functional heads: the cartography of syntactic structures. Vol. 4. Oxford: Oxford University Press.

Cinque, Guglielmo. 2010. The syntax of adjectives: a comparative study. Cambridge: MIT press. DOI: https://doi.org/10.7551/mitpress/9780262014168.003.0005

De Kuthy, Kordula. 1998. Splitting PP arguments from NPs: an argument raising approach and its interaction with lexical semantics. In Proceedings of the ESSLLI workshop "Topics in constraint-based Germanic syntax".

De Kuthy, Kordula \& Walt Detmar Meurers. 2001. On partial constituent fronting in German. The Journal of Comparative Germanic Linguistics 3(3). 143-205. DOI: https:// doi.org/10.1023/A:1011926510300

Dray, Nancy. 1987. Doubles and modifiers in English. Chicago: University of Chicago MA thesis.

Finkbeiner, Rita. 2012. Naja, normal und normal. Zur Syntax, Semantik und Pragmatik der $\mathrm{x}$-und-x-Konstruktion im Deutschen [On the syntax, semantics, and pragmatics 
of the x-and-x construction in German]. Zeitschrift für Sprachwissenschaft 31(1). 1-42. DOI: https://doi.org/10.1515/zfs-2012-0001

Finkbeiner, Rita. 2014. Identical constituent compounds in German. Word Structure 7(2). 182-213. DOI: https://doi.org/10.3366/word.2014.0065

Freywald, Ulrike. 2015. Total reduplication as a productive process in German. In Daniela Rossi (ed.), The why and how of total reduplication: current issues and new perspectives, vol. 39, 905-945. DOI: https://doi.org/10.1075/sl.39.4.06fre

Ghomeshi, Jila, Ray Jackendoff, Nicole Rosen \& Kevin Russell. 2004. Contrastive focus reduplication in English (the salad-salad paper). Natural Language \& Linguistic Theory 22. 307-357. DOI: https://doi.org/10.1023/B:NALA.0000015789.98638.f9

Hackert, Stephanie. 2013. Bahamian Creole structure dataset. Available online: https:// apics-online.info/contributions/12, received 08-21-2019.

Haegeman, Liliane. 2004. DP-periphery and clausal periphery: possessor doubling in West Flemish. In David Adger, Cécile De Cat \& George Tsoulas (eds.), Peripheries, 211-240. Springer. DOI: https://doi.org/10.1007/1-4020-1910-6_9

Halle, Morris \& Alec Marantz. 1993. Distributed morphology and the pieces of inflection. In Kenneth Hale \& S. Jay Keyser (eds.), The view from building 20, 111-176. Cambridge: MIT Press.

Haspelmath, Martin \& the APiCS consortium. 2013. Functions of reduplication. In Susanne Maria Michaelis, Philippe Maurer, Martin Haspelmath \& Magnus Huber (eds.), The atlas of pidgin and creole language structures, 100-104. Oxford: Oxford University Press.

Hohenhaus, Peter. 2004. Identical constituent compounding-a corpus-based study. Folia Linguistica 38(3-4). 297-332. DOI: https://doi.org/10.1515/flin.2004.38.3-4.297

Hole, Daniel. 2015. Arguments and adjuncts. In Tibor Kiss \& Artemis Alexiadou (eds.), Syntax. Theory and analysis. An international handbook, 1285-1321. Berlin \& New York: de Gruyter Mouton.

Horn, Laurence R. 1993. Economy and redundancy in a dualistic model of natural language. In Susanna Shore \& Maria Vilkuna (eds.), Sky 1993. 1993 yearbook of the Linguistic Association of Finland, 33-72. Helsinki: Mouton de Gruyter.

Horn, Laurence R. 2006. Speaker and hearer in neo-Gricean pragmatics. Waiguoyi 164. 2-26. DOI: https://doi.org/10.1515/iprg.2005.2.2.191

Horn, Laurence R. 2018. The lexical clone: pragmatics, prototypes, productivity. In Rita Finkbeiner \& Ulrike Freywald (eds.), Exactrepetition in grammar and discourse, 233-264. De Gruyter Mouton: Berlin \& Boston. DOI: https://doi.org/10.1515/97831105924 98-010

Huang, Yan. 2015. Lexical cloning in English: a neo-Gricean lexical pragmatics analysis. Journal of Pragmatics 86. 80-85. DOI: https://doi.org/10.1016/j.pragma.2015.06.005

Jackendoff, Ray. 1997. The architecture of the language faculty. Cambridge, MA: MIT Press.

Jackendoff, Ray. 2002. Foundations of language. Oxford: Oxford University Press. DOI: https://doi.org/10.1093/acprof:oso/9780198270126.001.0001

Jayaseelan, Karattuparambil A. 2001. IP-internal topic and focus phrases. Studia Linguistica 55(1). 39-75. DOI: https://doi.org/10.1111/1467-9582.00074

Keizer, Evelien. 2004. Postnominal PP complements and modifiers: a cognitive distinction. English Language \& Linguistics 8(2). 323-350. DOI: https://doi.org/10.1017/S1360 674304001406

Kentner, Gerrit. 2017. On the emergence of reduplication in German morphophonology. Zeitschrift für Sprachwissenschaft 36(2). 233-277. DOI: https://doi.org/10.1515/zfs2017-0010

Kingsbury, Roy \& Guy Wellman. 1986. Longman advanced English: teacher's guide. Harlow: Longman. 
Kouwenberg, Silvia (ed.). 2003. Twice as meaningful: reduplication in pidgins, creoles and other contact languages. London: Battlebridge.

Laenzlinger, Christopher. 2005. French adjective ordering: perspectives on DP-internal movement types. Lingua 115. 645-689. DOI: https://doi.org/10.1016/j.lingua.2003. 11.003

Larson, Richard K. 1988. On the double object construction. Linguistic Inquiry 19. 335-391.

Masià, Melania S. 2015. Adjectives of veracity as vagueness regulators. In Proceedings of Sinn und Bedeutung 19, 393-410.

Mau, Thorsten. 2002. Form und Funktion sprachlicher Wiederholung [Form and function of linguistic repetition]. Frankfurt a. M.: Peter Lang.

Medici, Mario. 1959. Il tipo caffè-caffè. Lingua Nostra 20. 84.

Müller, Gereon. 1998. Incomplete category fronting: a derivational approach to remnant movement in German. In Incomplete category fronting, 1-28. Dordrecht, Boston \& London: Springer. DOI: https://doi.org/10.1007/978-94-017-1864-6_1

Mutaka, Ngessimo \& Larry M. Hyman. 1990. Syllables and morpheme integrity in Kinande reduplication. Phonology 7(1). 73-119. DOI: https://doi.org/10.1017/S095267570000 1123

Radford, Andrew. 1988. Transformational grammar: a first course. New York: Cambridge University Press. DOI: https://doi.org/10.1017/CBO9780511840425

Roca, Francesc \& Avellina Suñer. 1998. Reduplicación y tipos de cuantificación [Reduplication and types of quantification]. Estudi general: Revista de la Facultat de Lletres de la Universitat de Girona 17. 37-66.

Rosch, Eleanor. 1978. Principles of categorization. In Eleanor Rosch \& Barbara Lloyd (eds.), Cognition and categorization, 27-48. Hillsdale, NJ: Erlbaum.

Scott, Gary-John. 2002. Stacked adjectival modification and the structure of nominal phrases. In Guglielmo Cinque (ed.), Functional structure in DP and IP, 91-120. Oxford: Oxford University Press.

Sigurðsson, Halldór Ármann \& Joan Maling. 2012. Silent heads. In Laura Brugé, Anna Cardinaletti, Giusti, Nicola Munaro \& Cecilia Poletto (eds.), Functional heads, 368-378. Oxford: Oxford University Press. DOI: https://doi.org/10.1093/acprof:oso/978019974 6736.003.0028

Song, Myounghyoun \& Chungmin Lee. 2011. CF-reduplication in English: dynamic prototypes \& contrastive focus effects. In Proceedings of SALT 21, 444-462. DOI: https://doi.org/10.3765/salt.v21i0.2590

Sproat, Richard \& Chilin Shih. 1991. The cross-linguistic distribution of adjective ordering restrictions. In Carol Perkins Georgopoulos \& Roberta Lynn Ishihara (eds.), Interdisciplinary approaches to language. Essays in honor of S.-Y. Kuroda, 565-593. Dordrecht: Kluwer. DOI: https://doi.org/10.1007/978-94-011-3818-5_30

Stolz, Thomas. 2009. Total reduplication: syndetic vs. asyndetic patterns in Europe. Grazer Linguistische Studien 17. 99-113.

Stolz, Thomas, Cornelia Stroh \& Ania Urdze. 2011. Total reduplication. The areal linguistics of a potential universal. Berlin: Akademie Verlag. DOI: https://doi.org/10.1524/ 9783050050973

Szendri, Kriszta. 2012. Focus movement can be destressing, but it need not be. In Ad Neeleman \& Reiko Vermeulen (eds.), The syntax of topic, focus, and contrast: an interface-based approach, 189-226. Berlin: Mouton de Gruyter.

Tescari Neto, Aquiles. 2013. On verb movement in Brazilian Portuguese: a cartographic study. Venice: Università Ca' Foscari di Venezi dissertation.

Travis, Lisa. 2003. Reduplication feeding syntactic movement. In Proceedings of the 2003 annual conference of the Canadian Linguistic Association, 236-247. 
Truswell, Robert. 2005. Non-restrictive adjective interpretation and association with focus. Oxford University Working Papers in Linguistics, Philology and Phonetics 133. 133-154.

van Gelderen, Elly. 2017. Syntax: an introduction to Minimalism. Amsterdam \& Philadelphia: John Benjamins. DOI: https://doi.org/10.1075/z.214

Varley, Nadia. 2014. Evidentiality straddling T- and C-domains. In Elisabeth Leiss \& Werner Abraham (eds.), Modes of modality: modality, typology, and Universal Grammar, 93-115. Amsterdam \& Philadelphia: John Benjamins. DOI: https://doi.org/10.1075/ slcs.149.03var

Wallenberg, Joel C. 2008. English weak pronouns and object shift. In Proceedings of the 26th West Coast Conference on Formal Linguistics, 489-497.

Whitton, Laura. 2006. The semantics of contrastive focus reduplication in English: does the construction mark prototype-prototype? Unpublished manuscript.

Whorf, Benjamin Lee. 1945. Grammatical categories. Language, 1-11. DOI: https://doi. org/10.2307/410199

Wierzbicka, Anna. 1991. Cross-cultural pragmatics: the semantics of human interaction. Berlin \& New York: Mouton de Gruyter.

Wilson, Deirdre. 2004. Relevance and lexical pragmatics. UCL Working Papers in Linguistics 16. 343-360.

How to cite this article: Bross, Fabian and Katherine Fraser. 2020. Contrastive focus reduplication and the modification puzzle. Glossa: a journal of general linguistics 5(1): 47.1-18. DOI: https://doi.org/10.5334/gjgl.1075

Submitted: 22 August 2019 Accepted: 17 March 2020 Published: 14 May 2020

Copyright: $\odot 2020$ The Author(s). This is an open-access article distributed under the terms of the Creative Commons Attribution 4.0 International License (CC-BY 4.0), which permits unrestricted use, distribution, and reproduction in any medium, provided the original author and source are credited. See http://creativecommons.org/licenses/by/4.0/.

$\mathrm{u}[\quad$ Glossa: a journal of general linguistics is a peer-reviewed open access journal published by Ubiquity Press.

OPEN ACCESS $\boldsymbol{\jmath}$ 